Jurnal SPORTIF: Jurnal Penelitian Pembelajaran

Vol. 6 No. 1, April 2020, pp. 157-172

doi) https://doi.org/10.29407/js_unpgri.v6i1.14005

\title{
Modifikasi pembelajaran: hybrid sport education-invasion games competence model terhadap performa permainan bola basket
}

\section{Modification of learning: hybrid sport education-invasion games competence model on basketball game performance}

\section{Boby Agustan ${ }^{1}$, Nurlan Kusmaedi ${ }^{2}$, Yudy Hendrayana ${ }^{2}$, Bambang Abduljabar $^{2}$, \& Agi Ginanjar ${ }^{3}$}

${ }^{1}$ Departemen Physical Education, Health, and Recreation, STKIP Muhammadiyah Kuningan, Jl. Syeh Maulana Akbar, Purwawinangun, Kuningan Regency, West Java Province, 45511, Indonesia

${ }^{2}$ Faculty of Sports Education and Health, Universitas Pendidikan Indonesia, Jl. Dr. Setiabudi No.229, Isola, Sukasari District, Bandung, West Java Province, 40154, Indonesia ${ }^{3}$ Departemen Physical Education, Health, and Recreation, STKIP Nahdlatul Ulama Indramayu, Jl. Raya Kaplongan No.28, Kaplongan, Karangampel, Indramayu Regency, West Java Province, 45283, Indonesia

Received: 18 December 2019; Revised: 12 January 2020; Accepted: 19 March 2020

\begin{abstract}
Abstrak
Tujuan dari penelitian ini adalah untuk menguji perbedaan performa permainan bola basket siswa sebelum dan sesudah menggunakan Hybrid Sport EducationInvasion Games Competence Model (SE-IGCM). Metode penelitian yang digunakan dalam penelitian ini adalah metode eksperimen dengan menggunakan the one-group pretest-posttest design. Partisipan di dalam penelitian ini sebanyak 20 siswa SMA kelas $X$ yang pilih dengan menggunakan systematic sampling. Instrumen dalam penelitian ini menggunakan Basketball Offensive Game Performance Instrument (BOGPI). Uji hipotesis dalam penelitian ini dengan menggunakan paired samples t-test. Hasil penelitian menyatakan bahwa terdapat perbedaan performa permainan bola basket pada siswa sesudah menggunakan Hybrid SE-IGCM. Penelitian ini memberikan penemuan bahwa Sport Education dengan menggunakan tiga tahap yang dimodifikasi dengan Invasion Games Competence Model dapat digunakan dalam pembelajaran pendidikan jasmani, khususnya dalam peningkatan performa permainan dalam bentuk invasi. Sehingga Hybrid SE-IGCM dapat digunakan dalam peningkatan performa permainan bola basket.
\end{abstract}

Kata kunci: bola basket, invasion games competence model, modifikasi, performa permainan, sport education.

\begin{abstract}
The purpose of this study is to observe differences in the students' basketball game performance before and after using Hybrid SE-IGCM (Sport EducationInvasion Games Competence Model). The research method used is experimental method using the one-group pretest-posttest design. Participants in this study are 20 high school class $X$ students who are selected using systematic sampling. The study instrument is Basketball Offensive Game Performance Instrument (BOGPI). Hypothesis testing employs paired samples $t$-test. The result shows the difference in the student basketball performance after using Hybrid SE-IGCM.
\end{abstract}

Correspondence author: Boby Agustan, STKIP Muhammadiyah Kuningan, Indonesia.

Email: bobyagustan@upmk.ac.id 
This research finds that SE which uses three stages with IGCM modification can be used in physical education learning, especially in improving the game performance in invasion form. As a result, Hybrid SE-IGCM can be used to improve basketball performance.

Keywords: basketball, game performance, invasion games competence model, modification, sport education.

\section{PENDAHULUAN}

Pembelajaran Pendidikan Jasmani (Penjas) harus meaningfull. Interaksi antara guru dan siswa dalam sebuah proses pembelajaran harus mengandung makna. Tidak hanya terjadi begitu saja, guru memberikan bola dan siswa melakukan aktivitas fisik. Konsep yang diberikan guru kepada murid tersusun dari awal pembelajaran hingga akhir pembelajaran. Langkah-langkah tersebut harus dipahami betul oleh siswa. Demikian juga dengan olahraga permainan. Olahraga yang menitikberatkan kepada pengalaman gerak siswa dengan kecabangan. Bola basket yang merupakan salah satu dari sekian cabang olahraga yang terdapat dalam kurikulum olaharaga permainan bola besar yang ada di sekolah. Hal yang paling mendasar bagi guru adalah bagaimana meramu sebuah model pembejaran yang akan diberikan kepada siswa sehingga siswa bisa mengikuti instruksi dari awal hingga akhir proses pembelajaran.

Faktor-faktor dalam melaksanakan pembelajaran khususnya dalam permainan bola basket, guru harus lebih kreatif dalam melaksanakan bentuk-bentuk permainan. Tantangan mengajar yang harus dihadapi sangat berat. Penciptaan kondidi belajar yang diharapkan dapat membuat siswa menarik untuk mengikuti pembelajaran bola basket di sekolah. Ini akan menjadi pemikiran konsep seorang pendidik untuk tetap memberikan bahan ajar sesuai dengan kurikulum walaupun dengan kondisi pembelajaran kurang memadai terutama dalam hal sarana dan prasarana. Pembelajaran olahraga dapat dimodifikasi sesuai dengan perkembangan mental anak dan tingkat partisipasi tinggi dalam tugas gerak (Juliantine, Subroto, \& Yudiana, 2013).

Modifikasi pembelajaran ke dalam bentuk permainan adalah cara yang bisa menarik minat para siswa untuk lebih semangat dalam 
mengikuti pembelajaran (Ghifari \& Hartati, 2019; Wijanarko, 2014). Siswa lebih tertarik untuk mengikuti pembelajaran penjas yang berbentuk permainan atau game (Ginanjar, 2018). Maka, guru harus mampu mengkreasikan bentuk permainan bola basket. Kompetisi bola basket unik tidak seperti olahraga lainnya, bola basket dapat dengan mudah dimodifikasi (Wissel, 2012). Lebih lanjut, proses pembelajaran berkembang dengan memecahkan masalah permainan individu dan kolektif melalui pertanyaan reflektif dan praktik bentuk-bentuk permainan yang dimodifikasi (Bunker \& Thrope, 1982). Modifikasi yang berprinsip pada Developmentally Appropriate Practice (DAP) diarahkan untuk membantu mengubah ke arah kemampuan belajar yang lebih baik dengan aktivitas belajar sesuai dengan tingkat perkembangan anak (Bahagia \& Suherman, 2000). Maka diperlukan strategi pembelajaran agar pembelajaran penjas dapat berjalan dengan lancar. Merekayasa proses pembelajaran dengan mengelola strategi yang tepat dan mengarah kepada kompetisi (Ginanjar, Suherman, Juliantine, \& Hidayat, 2019) dan model merupakan salah satu faktor yang tepat untuk membantu kinerja guru (Ginanjar, 2015).

Model yang digunakan dalam peneitian ini adalah Sport Education (SE). SE merupakan sebuah model pembelajaran yang memiliki perpaduan antara kemampuan dan kerjasama tim dalam satu musim (Siedentop, Hastie, \& Mars, 2011). Tujuan utama SE menjadi seseorang yang terdidik, bergairah, dan olahragawan yang berkompeten (Siedentop, 1994). Dalam pencapai SE tersebut didapat melalui 6 karakteristik SE yaitu: 1) musim, 2) afiliasi, 3) kompetisi formal, 4) acara puncak, 5) penyimpanan catatan, dan 6) perayaan (Siedentop, 1994). Banyak penelitian yang berkaitan dengan SE dengan menggunakan kecabangan bola basket telah banyak dilakukan dengan hasil yang berbeda-beda. SE meningkatkan tanggapan tentang suasana yang melibatkan tugas gerak dan dirasakan otonomi (Wallhead \& Ntoumanis, 2004). Siswa menunjukkan kompetensi yang signifikan dalam peran memimpin dan melatih yang terkait dengan musim (Hastie \& Sinelnikov, 2006). Siswa 
sangat patuh dengan tugas-tugas eksplisit dalam sistem tugas manajerial dan instruksional (Sinelnikov \& Hastie, 2008). Perubahan signifikan siswa yang termotivasi dalam persepsi kenikmatan dan kepuasan dalam SEM (Perlman, 2010). Siswa yang terlibat dalam SE memberikan tingkat pernyataan dukungan otonomi yang jauh lebih tinggi pada fase pembelajaran menggunakan SE (Perlman, 2012b). SEM memberikan kesempatan kepada siswa yang termotivasi untuk terlibat dalam aktivitas fisik tingkat (Perlman, 2012a). Kontak yang lama dengan fitur pedagogis SE mengembangkan ikatan sosial siswa (Wallhead, Garn, Vidoni, \& Youngberg, 2013). SE menyakup motivasi yang lebih berpusat dalam program penjas (Wallhead, Garn, \& Vidoni, 2014). Berpartisipasi dalam beberapa musim SE (salah satunya bola basket) mengarah pada pengembangan peran siswa yang lebih baik dan rasa bermain yang lebih kuat (Wahl-alexander, Sinelnikov, \& Curtner-smith, 2016). Terdapat perbedaan SEM cabang olahraga bola basket dan SEM cabang olahraga bulu tangkis terhadap orientasi olahraga siswa (Ginanjar dkk., 2019).

Dari berbagai hasil penelitian SE yang menggunakan cabang olahraga bola basket, maka penelitian ini akan menggunakan program SE yang terdiri dari tiga tahap yaitu: 1) skill/tactical development; 2) inter/intra team games with practices, 3) dan postseason (Ginanjar et al., 2019; Perlman, 2012a) dengan menggunakan modifikasi Invasion Games Competence Model (IGCM) (Farias, Mesquita, \& Hastie, 2015; Mesquita, Farias, \& Hastie, 2012; Musch dkk., 2002). IGCM secara konsep terstruktur erat dengan TGfU, tetapi juga menyerupai tujuan SE, yaitu, untuk menciptakan konteks olahraga yang otentik (Musch dkk., 2002). IGCM dianggap sebagai pendekatan inovatif karena sifat spesifik dari permainan invasi dan pentingnya pengajaran khusus dipertimbangkan (Belka, 2004), lebih lanjut lagi IGCM mempertimbangkan fakta bahwa tugas belajar harus selaras dengan tuntutan situasional terkait dengan permainan bentuk-bentuk dasar game invasi (Mesquita dkk., 2012), yang mana permaian bola basket merupakan salah satu permainan dalam bentuk invasi. Dalam IGCM, kompetensi siswa sebagai pemain mencakup 
kemampuan untuk mengidentifikasi dan memproses informasi yang relevan dalam konteks spesifik game invasi dan untuk memutuskan dan mengeksekusi secara efisien keterampilan yang khusus untuk sepak bola, bola tangan, atau bola basket (Farias dkk., 2015). IGCM menggabungkan sejumlah prinsip yang selaras dengan premis pedagogis dari pendekatan pembelajaran yang berpusat pada siswa, sehingga mengadopsi acara kompetisi selama kelas di mana siswa berpartisipasi tidak hanya sebagai pemain tetapi juga dalam peran yang mendukung (yaitu, siswa sebagai pelatih dan wasit) (Farias dkk., 2015). Pada dasarnya, model ini sangat fokus pada sifat spesifik dari konten taktis, keterampilan, dan masalah permainan dari permainan invasi (Musch dkk., 2002). Di sisi lain, model ini memegang fokus didaktik yang kuat mengingat bahwa tugas-tugas pembelajaran menggabungkan bentuk-bentuk permainan yang sesuai yang dirancang untuk memenuhi karakteristik siswa dan tingkat keterampilan (Farias dkk., 2015). Lebih lanjut lagi, konten taktis dan keterampilan permainan invasi diajarkan melalui bentuk permainan yang berbeda yaitu: 1) basic game forms (BGFs), 2) partial game forms (PGFs), 3) dan game-like tasks (GLTs) (Musch dkk., 2002). Jadi, program SE dalam penelitian ini adalah IGCM yang memiliki kemiripan dalam setiap tahapnya.

Dari keseluruhan pemaparan di atas, SE dan IGCM dapat dikatakan sebagai Hybrid SE-IGCM (Farias dkk., 2015) yang mana dalam penelitian tersebut menggunakan cabang olahraga sepak bola. Sehingga dalam penelitian ini akan menggunakan cabang olahraga bola basket berkaitan dengan minimnya penelitian agar menggunakan program pembelajaran dalam permainan invasi yang berbeda (Farias dkk., 2015). Maka, tujuan dari penelitian ini untuk menguji perbedaan performa permainan bola basket siswa sebelum dan sesudah menggunakan Hybrid SE-IGCM.

\section{METODE}

Metode yang digunakan adalah eksperimen dengan the one-group pretest-posttest design. Partisipan dalam penelitian ini sebanyak 182 
siswa SMAN kelas $\mathrm{X}$ yang kemudian diambil sebanyak 20 orang dalam kelas penelitian dengan menggunakan systematic sampling, sehingga peneliti mengambil sampel dengan menggunakan kelipatan 8 dan didapat sebanyak 20 orang sampel. Treatment yang digunakan dengan menggunakan Hybrid SE-IGCM yang mana merupakan gabungan dari SE dan IGCM. Fitur struktural seperti peran setiap siswa didapat dari SE, dengan menggunakan tiga tahap dengan 5 pertemuan setiap tahapnya dengan total 15 pertemuan (Perlman, 2012a), yang diadaptasi oleh hasil karya Ginanjar (2019) dengan interrater reliability 0.94 pada perencanaan dan 0.73 pada implementasi. Untuk tugas pembelajaran dengan menggunakan kerangka didaktik pada IGCM (Mesquita dkk., 2012). Dalam SE siswa dibagi ke dalam 3 tim yang berpartisipasi dalam serangkaian latihan dan kompetisi formal yang mengarah ke acara puncak. Dari 20 siswa yang terlibat dalam satu tim terdiri dari 1 orang pelatih, 1 orang manajer tim, dan 3 orang pemain termasuk kapten tim, sehingga total secara keseluruhan dari 3 tim tersebut sebanyak 15 orang. Kemudian 2 orang berperan sebagai wasit, 2 orang sebagai pencatat skor, dan 1 peran sebagai publikasi. Sehingga data yang diambil berkaitan dengan performa permainan bola basket yang berasal dari 12 orang siswa yang berperan sebagai pemain.

Pada tahap skill/tactical development di SE lebih menekankan kepada kemampuan keterampilan gerak olahraga yang akan digunakan (Ginanjar dkk., 2019) yang dimodifikasi dengan menggunakan BGFs di IGCM yang merupakan versi modifikasi dari permainan formal yang bertujuan untuk memfasilitasi tanggapan pemain terhadap masalah tertentu yang terkait dengan struktur permainan invasi (Mesquita dkk., 2012). Pada tahap inter/intra team games with practices di SE menekankan kepada kompetisi di dalam tim untuk menghadapai pertandingan antar tim pada tahap selanjutnya (Ginanjar dkk., 2019), yang dimodifikasi dengan menggunakan PGFs di IGCM dirancang untuk memecahkan masalah strategis yang spesifik dengan memaksakan kondisi, perubahan aturan, dan modifikasi peralatan pada permainan 
(Mesquita dkk., 2012). Pada tahap postseason di SE yang merupakan merupakan refleksi dari tahapan-tahapan sebelumnya dengan adanya kompetisi (Ginanjar dkk., 2019), yang dimodifikasi dengan menggunakan GLTs di IGCM untuk memperkenalkan dan meningkatkan aspek keterampilan khusus tertentu, menjaga tuntutan situasional PGFs dengan cara ini kinerja keterampilan permainan ditingkatkan tetapi terintegrasi dengan komponen lain dari permainan (Mesquita dkk., 2012). Untuk lebih jelas dalam treatment dapat di lihat pada tabel 1.

Instrumen di dalam penelitian ini dengan menggunakan Basketball Offensive Game Performance Instrument (BOGPI), tata cara penggunaan instrumen dengan bermain $2 \times 10$ menit 3 vs 3 . Instrumen tersebut memilki interrater reliability sebesar $99 \%$ dan alpha reliability coefficient untuk skala total sebesar 0,95 (Chen, Hendricks, \& Zhu, 2016). Teknik analisis data untuk mengetahui deskriptif data sebelum dan sesudah diberikan treatment rata-rata dan simpangan baku dianalisis dengan bantuan Statistical Package for the Social Sciences (SPSS). Uji normalitas yang merupakan uji prasyarat menggunakan shapiro-wilk dianalisis dengan bantuan SPSS. Untuk uji hipoetis menggunakan paired samples ttest dianalisis dengan bantuan SPSS.

Tabel 1. Program Pembelajaran Hybrid SE-IGCM Bola Basket

\begin{tabular}{|c|c|c|c|}
\hline $\begin{array}{l}\text { Tahapan } \\
\text { Musim }\end{array}$ & $\begin{array}{l}\text { Musim } \\
\text { ke }\end{array}$ & $\begin{array}{c}\text { Komponen } \\
\text { Sport Education }\end{array}$ & $\begin{array}{c}\text { Komponen Invasion Games } \\
\text { Competence Model }\end{array}$ \\
\hline \multirow{3}{*}{$\begin{array}{l}\text { Skill/tactical } \\
\text { development }\end{array}$} & 1 & $\begin{array}{l}\text { - } \text { Pengantar bola } \\
\text { basket } \\
\text { - } \text { Membutuhkan } \\
\text { penilaian } \\
\text { - Identifikasi pelatih tim } \\
\text { - Seleksi tim dan nama } \\
\text { tim } \\
\text { - Aturan peran siswa }\end{array}$ & $\begin{array}{l}\text { GLTs (3vs3) semua tim terlibat } \\
\text { Tim A, Tim B, Tim C (Pretest } \\
\text { menggunakan tata cara BOGPI) }\end{array}$ \\
\hline & 2 & $\begin{array}{l}\text { - Latihan tim } \\
\text { - Passing }\end{array}$ & $\begin{array}{l}\text { BGFs setiap tim dengan tim } \\
\text { masing-masing ( } 2 \mathrm{vs} 1) 2 \text { offence } \\
\text { dan } 1 \text { defence permainan hanya } \\
\text { menggunakan passing dengan } \\
\text { sasaran menembak ke arah tiang } \\
\text { yang telah disediakan }\end{array}$ \\
\hline & 3 & $\begin{array}{l}\text { - Latihan tim } \\
\text { - Dribbling }\end{array}$ & $\begin{array}{l}\text { BGFs setiap tim dengan tim } \\
\text { masing-masing ( } 2 \text { vs } 1) 2 \text { offence } \\
\text { dan } 1 \text { defence permainan hanya } \\
\text { menggunakan passing dan } \\
\text { dribbling dengan sasaran }\end{array}$ \\
\hline
\end{tabular}


Boby Agustan, Nurlan Kusmaedi, Yudy Hendrayana, Bambang Abduljabar, \& Agi Ginanjar Modifikasi pembelajaran: hybrid sport education-invasion games competence model terhadap performa permainan bola basket

Lanjutan tabel 1. Program Pembelajaran Hybrid SE-IGCM Bola Basket

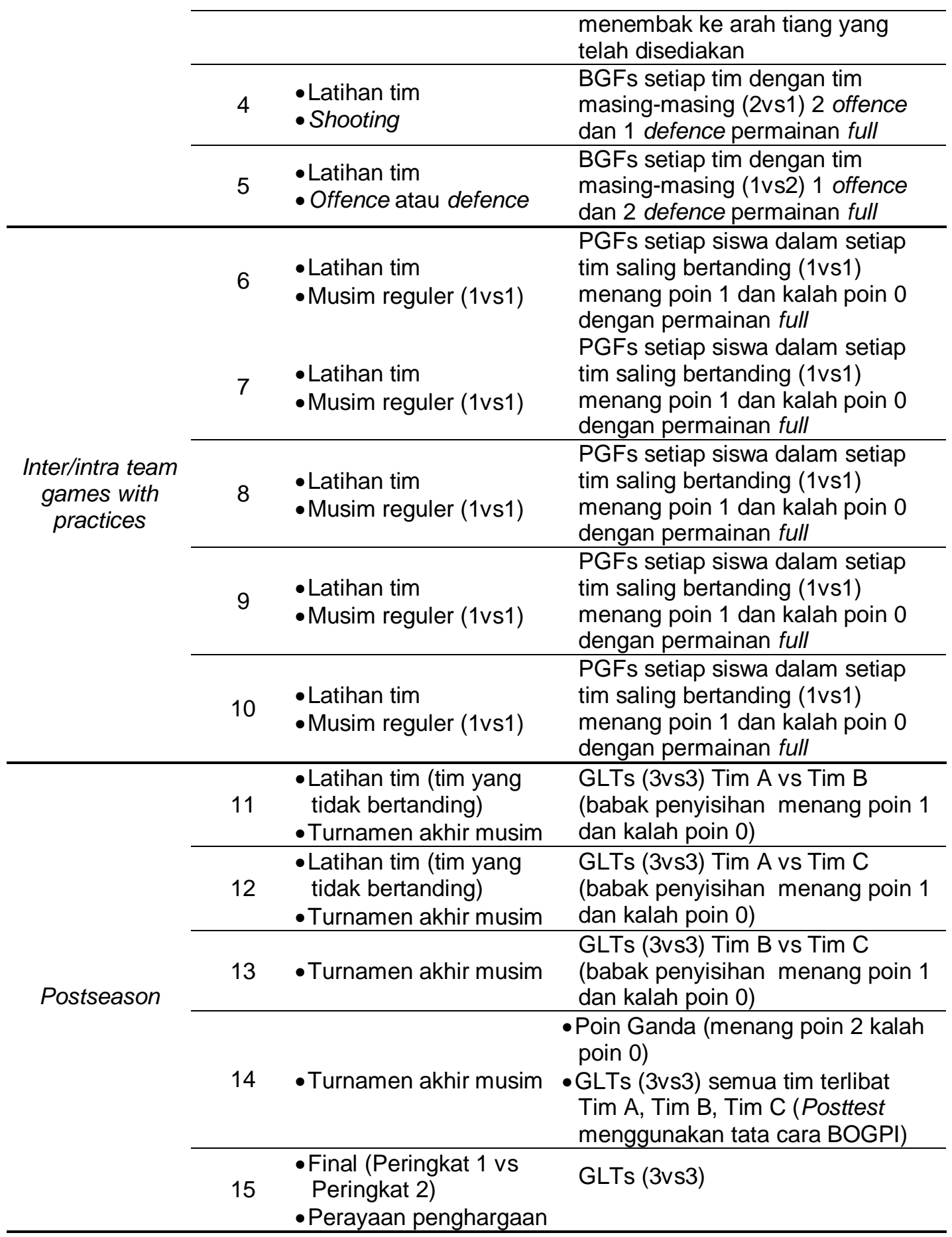

HASIL

Deskriptif data yang diperoleh pada pre-test didapat nilai mean $=$ $42.42, \mathrm{SD}=1.51$ dan pada post-test didapat mean $=44.58, \mathrm{SD}=1.73$ yang dapat dilihat pada tabel 2 . 
Tabel 2. Hasil Deskriptif Data

\begin{tabular}{ccc}
\hline & Hasil Tes Awal & Hasil Tes Akhir \\
\hline $\mathrm{N}$ & 12 & 12 \\
Mean & 42.42 & 44.58 \\
$\mathrm{SD}$ & 1.51 & 1.73 \\
\hline
\end{tabular}

Uji normalitas sebagai uji prasyarat dengan menggunakan shapirowilk untuk mengetahui data berdistribusi normal atau tidak. Pada pre-test sebesar 0.955 dengan signifikansi $0.72>0.05$ dan pada post-test sebesar 0.897 dengan signifikansi $0.14>0.05$ maka kedua data tersebut berdistribusi normal yang dapat dilihat pada tabel 3 .

Tabel 3. Hasil Uji Normalitas

\begin{tabular}{ccc}
\hline & Shapiro-Wilk & Sig. \\
\hline Tes Awal & 0.955 & $0.72>0.05$ \\
Tes Akhir & 0.897 & $0.14>0.05$ \\
\hline
\end{tabular}

Uji hipotesis didapat thitung $=8.99$ dengan signifikansi $0.00<0.05$ yang dapat dilihat pada Tabel 4 . Sehingga dapat diartikan bahwa terdapat perbedaan performa permainan bola basket siswa sebelum dan sesudah menggunakan Hybrid SE-IGCM.

Tabel 4. Hasil Uji Hipotesis

\begin{tabular}{ccc}
\hline & thitung & Sig. \\
\hline $\begin{array}{c}\text { Tes Akhir }><\text { Tes } \\
\text { Awal }\end{array}$ & 8.99 & $0.00<0.05$ \\
\hline
\end{tabular}

\section{PEMBAHASAN}

Penekanan dalam penelitian ini untuk menguji perbedaan performa permainan bola basket siswa sebelum dan sesudah menggunakan Hybrid SE-IGCM. Hasil penelitian menyatakan bahwa performa permainan bola basket setelah diberikan treatment dengan menggunakan Hybrid SEIGCM memberikan tingkat signifikansi yang lebih tinggi dibandingkan dengan performa permainan bola basket sebelum diberikan treatment dengan menggunakan Hybrid SE-IGCM. 
Sebelum bermain bola basket siswa diharapkan memiliki keterampilan yang baik. Istilah terampil digunakan untuk menggambarkan tingkat kemampuan anak didik yang berbeda-beda. Kemampuan menyelesaikan tugas gerak tertentu, terlihat dari kualitas seberapa jauh anak didik menampilkan performa yang ditugaskan oleh guru dengan tingkat keberhasilan yang dicapai. Tiap tahapan tugas gerak memberikan kontribusi kualitas keterampilan gerak, karena anak didik yang memiliki kualitas adalah anak didik yang mampu melakukan tugas gerak secara efisien dan sistematis. Permainan bola basket sebagai media pembelajaran merupakan suatu perpaduan bagaimana caranya bertahan dan bagaimana cara menyerang, maka dari itu seorang pemain harus menguasai dasar dari permainan bola basket yaitu menguasai teknik dan keterampilan dasar sehingga dapat bermain dengan baik. Untuk dapat menguasai keterampilan gerak yang baik maka diperlukan proses belajar berlatih dalam jangka waktu relatife tidak sebentar, sehingga seseorang yang ingin terampil dalam permainan bola basket diperlukan proses latihan yang terukur dan sistematis dan didukung oleh unsur-unsur gerak yang baik (Abidin, 1999).

Oleh karena itu dalam penelitian ini sebelum siswa dapat bermain bola basket dengan baik pada tahap skill/tactical development di SE menekankan pada kemampuan keterampilan gerak kecabangan olahraga (Ginanjar dkk., 2019), siswa dilatih untuk dapat meningkatakan keterampilan bola basket. Agar siswa lebih dapat terampil maka dalam penelitian ini peneliti memberikan program latihan keterampilan dasar bermain bola basket dengan menggunakan bentuk permainan yang dimodifiksi dalam permainan bola basket 2 orang siswa melakukan offence melawan 1 orang siswa yang melakukan defence begitu juga sebaliknya 1 orang siswa melakukan offence melawan 2 orang siswa yang melakukan defence dengan runtutan teknik passing, dribbling, dan shooting yang merupakan teknik yang paling sering digunakan dalam permainan bola basket. Bentuk latihan tersebut merupakan modifikasi IGCM, sehingga penelitian ini mendukung bahwa dengan IGCM dengan 
kerangka tugas BGFs dapat digunakan dalam meningkatkan keterampilan bermain bola basket. BGFs yang merupakan versi modifikasi dari permainan formal yang bertujuan untuk memfasilitasi tanggapan pemain terhadap masalah tertentu yang terkait dengan struktur permainan invasi (Mesquita dkk., 2012).

Pada tahap inter/intra team games with practices di SE menekankan kepada kompetisi di dalam tim untuk menghadapai pertandingan antar tim pada tahap selanjutnya (Ginanjar dkk., 2019). Setelah melewati tahapan pertama, agar menjaga siswa dapat bermain dengan sebenarnya peneliti memberikan pelatihan dengan melakukan kompetisi di dalam setiap tim yang terlibat dalam program pembelajaran. Setiap siswa dalam setiap tim saling bertanding dengan memodifikasi permainan (1vs1), kemudian diberikan hadiah atau poin setelah siswa melakukan pertandingan tersebut, siswa yang menang diberikan poin 1 dan siswa yang kalah diberikan poin 0 . Kemudian peneliti pun mencatat hasil poin yang didapat setiap siswa untuk diumumkan pada pertemuan akhir di tahap inter/intra team games with practices ini dalam setiap pertemuannya. Bentuk latihan tersebut merupakan modifikasi IGCM dengan menggunakan kerangka tugas PGFs dengan kompetisi antar pemain di dalam timnya yang aturan permaianan dirubah (1vs1) dan diberikan poin. PGFs dirancang untuk memecahkan masalah strategis yang spesifik dengan perubahan aturan untuk mengatasi konten taktis yang berbeda untuk menyelesaikan masalah taktis yang berkaitan dengan penilaian (Mesquita dkk., 2012).

Pada tahap post season di SE yang merupakan merupakan refleksi dari tahapan-tahapan sebelumnya dengan adanya kompetisi (Ginanjar dkk., 2019). Dalam tahap ini terdapat kompetisi yang mana kompetisi tersebut terdiri dari tiga bagian. Pertama, babak penyisihan semua tim terlibat dalam kompetisi penuh dengan sistem bertemu, tim yang menang diberikan poin 1 dan tim yang kalah diberikan poin 0 . Kedua, babak poin ganda yang merupakan salah satu strategi peneliti agar siswa tetap terjaga dalam performa permainan bola basket dengan memberikan poin 
yang lebih agar tim yang sebelumnya kalah dapat langsung mendapatkan poinn yang lebih besar jika memenangkan pertandingan agar dapat bertanding di babak final. Ketiga, final dan perayaan ini merupakan tahap akhir dengan adanya perayaan penghargaan sesuai dengan fitur SE, tim yang masuk final diambil berdasarkan hasil kompetisi pada peringkat 1 vs peringkat 2. Bentuk kompetisi disesuaikan dengan modifikasi IGCM kerangka tugas GLTs dengan kompetisi sesuai dengan fitur SE.

Oleh karena itu penelitian ini memberikan pandangan baru bahwa dengan Hybrid SE dengan tiga tahap yaitu: 1) skill/tactical development; 2) inter/intra team games with practices; 3) dan postseason (Ginanjar dkk., 2019) yang dimodifikasi dengan menggunakan IGCM dengan kerangka tugas BGFs, PGFs), dan GLTs (Musch dkk., 2002) yang diadaptasi oleh (Mesquita dkk., 2012) dapat meningkatkan performa permainan kususnya dalam permainan bola basket. Hasil peneliti ini juga mendukunng hasil penelitian terdahulu yang berkaitan dengan SE-IGCM yang menytakan SE ditopang oleh struktur tugas pembelajaran yang disediakan oleh IGCM menawarkan siswa kesempatan untuk meningkatkan pelaksanaan keterampilan, serta pengambilan keputusan taktis mereka (Mesquita dkk., 2012). Aplikasi gabungan dari SE (lingkungan belajar otentik) dan IGCM (dengan tugas-tugas pembelajaran yang difokuskan pada konten taktis khusus dan keterampilan) mempromosikan peningkatan kinerja, pemahaman permainan siswa, dan meningkatkan korelasi antara kedua konstruksi (Farias dkk., 2015). Korelasi meningkat sepanjang waktu antara indeks struktur taktis dan performa permainan dan model prediksi performa permainan yang diperluas hingga mencakup empat struktur taktis (Farias, Mesquita, \& Hastie, 2018). IGCM efektif dalam meningkatkan kinerja permainan siswa dalam permainan invasi (Tallir, Lenoir, Valcke, \& Musch, 2007), khususnya untuk anak perempuan dan siswa tingkat keterampilan rendah (Ricardo \& Graca, 2008). 


\section{KESIMPULAN DAN SARAN}

\section{Kesimpulan}

Hasil penelitian menyatakan bahwa performa permainan bola basket setelah diberikan treatment dengan menggunakan Hybrid SEIGCM memberikan tingkat signifikansi yang lebih tinggi dibandingkan dengan performa permainan bola basket sebelum diberikan treatment dengan menggunakan Hybrid SE-IGCM. Hybrid dari SE (lingkungan belajar otentik) dan IGCM (dengan tugas-tugas pembelajaran yang difokuskan pada konten taktis khusus dan keterampilan) mempromosikan peningkatan kinerja, pemahaman permainan siswa, dan meningkatkan korelasi antara kedua konstruksi.

\section{Saran}

Penelitian ini menyarankan agar melakukan penelitian lebih lanjut lagi berkaitan dengan jumlah partisipann yang lebih banyak agar hasil penelitian dapat digeneralisasikan dan melakukan penelitian dengan menggunakan cabang olahraga invasi lainnya.

\section{REFERENSI}

Abidin, A. (1999). Buku Penuntun Bola basket Kembar. Jakarta: Raja Grafindo Persada.

Bahagia, Y., \& Suherman, A. (2000). Prinsip-prinsip Pengembangan Dan Modifikasi Cabang Olahraga. Depdiknas.

Belka, D. E. (2004). Combining and Sequencing Games Skills. Journal of Physical Education, Recreation \& Dance, 75(4), 23-27. https://doi.org/10.1080/07303084.2004.10609263

Bunker, D., \& Thrope, R. (1982). A Model for the Teaching of Games in Secondary Schools. Bulletin of Physical Education, 10, 9-16.

Chen, W., Hendricks, K., \& Zhu, W. (2016). Development and Validation of the Basketball Offensive Game Performance Instrument. Journal of Teaching in Physical Education, 32(1), 100-109. https://doi.org/10.1123/jtpe.32.1.100

Crum, B., Radstake, J., \& Regterchot, M. (2006). Hakikat Permainan Invasi. In Y. Bahagia (Ed.), Permainan Invasi (pp. 1-25). Bandung: FPOK Pendor UPI Bandung.

Farias, C. F., Mesquita, I. R., \& Hastie, P. A. (2015). Erratum. Journal of Teaching in Physical Education, 34, 363-388. https://doi.org/10.1123/jtpe.2015-0189 
Farias, C. F., Mesquita, I. R., \& Hastie, P. A. (2018). Student game-play performance in invasion games following three consecutive hybrid Sport Education seasons. European Physical Education Review, 122. https://doi.org/10.1177/1356336X18769220.

Ghifari, M. R. A. \& Hartati, S. C. Y. (2019). Pengaruh Penerapan Modifikasi Permainan Softball Terhadap Motivasi Belajar Siswa Inklusi. Jurnal Pendidikan Olahraga dan Kesehatan, 7(3), 191-194.

Ginanjar, A. (2015). The Influence of Inquiry Method in Motivating the SMP' Student. Jurnal Kependidikan, 45(2), 123-129. https://doi.org/http://dx.doi.org/10.21831/jk.v45i2.7489

Ginanjar, A. (2018). the Tactical Games Modelsand Motivation Learningof Physical Fitness the Vocational School Students. Jurnal Kependidikan: Penelitian Inovasi Pembelajaran, 2(2), 409-419. https://doi.org/10.21831/jk.v2i2.10746

Ginanjar, A. (2019). Pengaruh Sport Education Model dan Tingkat Fundamental Movement Skill terhadap Aktivitas Fisik dan Kompetitif Siswa dalam Pendidikan Jasmani. (Disertasi). Universitas Pendidikan Indonesia.

Ginanjar, A., Suherman, A., Juliantine, T., \& Hidayat, Y. (2019). Sports Orientation During Learning Team or Individual Sports Using Sport Education Model. Cakrawala Pendidikan, 38(2), 377-386. https://doi.org/10.21831/cp.v38i2.24021

Hastie, P. A., \& Sinelnikov, O. A. (2006). Russian students' participation in and perceptions of a season of Sport Education. European Physical Education Review, 12(2), 131-150. https://doi.org/10.1177/1356336X06065166

Juliantine, T., Subroto, T., \& Yudiana, Y. (2013). Model-model Pembelajaran Pendidikan Jasmani. Bandung: FPOK Universitas Pendidikan Indonesia Bandung.

Mesquita, I. R., Farias, C. F., \& Hastie, P. A. (2012). The impact of a hybrid Sport Education-Invasion Games Competence Model soccer unit on students' decision making, skill execution and overall game performance. European Physical Education Review, 18(2), 205-219. https://doi.org/10.1177/1356336X12440027

Musch, E., Mertens, B., Timmers, E., Mertens, T., Graca, A., Taborsky, F., \& Vonderlynck, V. (2002). An innovative didactical invasion games model to teach basketball and handball. The 7th Annual Congress of the European College of Sport Science. Athens, Greece.

PERBASI. (2008). Peraturan Permainan Bola basket. Jakarta: Pengurus Besar Peraturan Permainan Bola basket Seluruh Indonesia.

Perlman, D. (2010). Change in Affect and Needs Satisfaction for Amotivated Students within the Sport Education Model. Journal of Teaching in Physical Education, 29, 433-445. 
Perlman, D. (2012a). The influence of the Sport Education Model on amotivated students' in-class physical activity. European Physical Education Review, 18(3), 335-345. https://doi.org/10.1177/1356336X12450795

Perlman, D. (2012b). The influence of the Sport Education Model on developing autonomous instruction. Physical Education and Sport Pedagogy, 17(5), 493-505. https://doi.org/10.1080/17408989.2011.594430

Ricardo, V., \& Graca, A. (2008). Developing secondary school students' competence in playing basketball: Analysis of an experimental teaching unit. The Teaching Games for Understanding 2008 International Conference, University of British Columbia. British Columbia, Canada.

Siedentop, D. (1994). Sport Education: Quality PE Through Positive Sport Experiences. Champaign: Human Kinetics.

Siedentop, D., Hastie, P. A., \& Mars, H. van der. (2011). Complete Guide to Sport Education (2nd ed.). Champaign: Human Kinetics.

Sinelnikov, O., \& Hastie, P. A. (2008). Teaching sport education to Russian students: An ecological analysis. European Physical Education Review, 14(2), 203-222. https://doi.org/10.1177/1356336X08090706

Tallir, I. B., Lenoir, M., Valcke, M., \& Musch, E. (2007). Exported Abstract record (s). International Journal of Sport Psychology, 38(3), 263-282.

Wahl-alexander, Z., Sinelnikov, O., \& Curtner-smith, M. (2016). A longitudinal analysis of students' autobiographical memories of participation in multiple Sport Education seasons. European Physical Education Review, 1-16. https://doi.org/10.1177/1356336X15624246

Wallhead, T. L., Garn, A. C., \& Vidoni, C. (2014). Effect of a Sport Education Program on Motivation for Physical Education and Leisure-Time Physical Activity. Research Quarterly for Exercise and Sport, $\quad$ 85(4),

478-487. https://doi.org/10.1080/02701367.2014.961051

Wallhead, T. L., Garn, A. C., Vidoni, C., \& Youngberg, C. (2013). Game Play Participation of Amotivated Students During Sport Education. Journal of Teaching in Physical Education, 32, 149-165.

Wallhead, T. L., \& Ntoumanis, N. (2004). Effects of a Sport Education Intervention on Students' Motivational Responses in Physical Education. Journal of Teaching in Physical Education, 23(1), 4-18. https://doi.org/10.1123/jtpe.23.1.4.

Wijanarko, D. R. (2014). Pengaruh Modifikasi Permainan Sepakbola Terhadap Motivasi Siswa dalam Pembelajaran Pendidikan Jasmani, Olahraga dan Kesehatan (Studi Pada Siswa Kelas VII SMP Negeri 2 
Boby Agustan, Nurlan Kusmaedi, Yudy Hendrayana, Bambang Abduljabar, \& Agi Ginanjar Modifikasi pembelajaran: hybrid sport education-invasion games competence model terhadap performa permainan bola basket

Candi Sidoarjo). Jurnal Pendidikan Olahraga dan Kesehatan, 2(3), 591-594.

Wissel, H. (2012). Basketball Steps to success (3rd ed.). Champaign: Human Kinetics. 